Research article

\title{
Kefir consumption does not alter plasma lipid levels or cholesterol fractional synthesis rates relative to milk in hyperlipidemic men: a randomized controlled trial

\author{
Marie-Pierre St-Onge ${ }^{1}$, Edward R Farnworth ${ }^{2}$, Tony Savard ${ }^{2}$, Denise Chabot ${ }^{2}$,
} Akier Mafu ${ }^{2}$ and Peter JH Jones*1
}

\begin{abstract}
Address: ${ }^{1}$ School of Dietetics and Human Nutrition, McGill University, Ste-Anne-de-Bellevue, Canada and ${ }^{2}$ Food Research and Development Center, Agriculture Canada, St-Hyacinthe, Canada

E-mail: Marie-Pierre St-Onge - mstong@po-box.mcgill.ca; Edward R Farnworth - farnworthed@em.agr.ca;

Tony Savard - farnworthed@em.agr.ca; Denise Chabot - chabotd@em.agr.ca; Akier Mafu - farnworthed@em.agr.ca;

Peter JH Jones* - jonesp@ macdonald.mcgill.ca

${ }^{*}$ Corresponding author
\end{abstract}

Published: 22 January 2002

Received: 9 July 2001

BMC Complementary and Alternative Medicine 2002, 2:I

Accepted: 22 January 2002

This article is available from: http://www.biomedcentral.com//472-6882/2/I

(c) 2002 St-Onge et al; licensee BioMed Central Ltd. Verbatim copying and redistribution of this article are permitted in any medium for any purpose, provided this notice is preserved along with the article's original URL.

\begin{abstract}
Background: Fermented milk products have been shown to affect serum cholesterol concentrations in humans. Kefir, a fermented milk product, has been traditionally consumed for its potential health benefits but has to date not been studied for its hypocholesterolemic properties.

Methods: Thirteen healthy mildly hypercholesterolemic male subjects consumed a dairy supplement in randomized crossover trial for 2 periods of $4 \mathrm{wk}$ each. Subjects were blinded to the dairy supplement consumed. Blood samples were collected at baseline and after $4 \mathrm{wk}$ of supplementation for measurement of plasma total, low-density lipoprotein, and high-density lipoprotein cholesterol and triglyceride concentrations, as well as fatty acid profile and cholesterol synthesis rate. Fecal samples were collected at baseline and after 2 and 4 wk of supplementation for determination of fecal short chain fatty acid level and bacterial content.

Results: Kefir had no effect on total cholesterol, low-density lipoprotein cholesterol, high-density lipoprotein cholesterol or triglyceride concentrations nor on cholesterol fractional synthesis rates after 4 wk of supplementation. No significant change on plasma fatty acid levels was observed with diet. However, both kefir and milk increased $(p<0.05)$ fecal isobutyric, isovaleric and propionic acids as well as the total amount of fecal short chain fatty acids. Kefir supplementation resulted in increased fecal bacterial content in the majority of the subjects.

Conclusions: Since kefir consumption did not result in lowered plasma lipid concentrations, the results of this study do not support consumption of kefir as a cholesterol-lowering agent.
\end{abstract}

\section{Background}

Kefir has anecdotally been recommended for consumption by healthy people to lower risk of chronic diseases in
Soviet countries [1]. In these countries, kefir is provided to patients for clinical treatment of gastrointestinal and metabolic diseases, hypertension, ischemic heart disease and 
allergy [1]. However, supporting literature on kefir's efficacy or mechanism of action to alleviate these symptoms is scarce [2]. Other fermented dairy products such as yogurt and Gaio have been reported to lower serum cholesterol concentrations in animals [3-7] and humans [813]. Although contradictory results have been obtained [14-16], the majority of results from these reports indicate that fermented dairy products, possibly including kefir, possess hypocholesterolemic properties.

Consumption of fermented milk has the potential to increase gut bacterial colonization via a protective effect of milk protein for survival through the gastrointestinal transit [17]. Yogurt has been reported to have hypocholesterolemic properties [3-13]. Kefir contains a greater number of different bacteria than yogurt. Therefore, it is not known whether consumption of kefir will have a hypocholesterolemic effect in humans. The aim of the present research was therefore to determine whether kefir supplementation would alter plasma total cholesterol, HDLcholesterol, LDL-cholesterol, triglycerides, and fatty acid levels in mildly hypercholesterolemic men. Furthermore, analysis of changes in fecal short chain fatty acid (SCFA) content and cholesterol fractional synthesis rate were also conducted in order to elucidate a mechanism of action for any effects of kefir observed.

\section{Methods \\ Study design and subjects}

Non-smoking men were recruited through advertisements in local newspapers. Subjects were included in the study if their total serum cholesterol levels were between 6 and 10 $\mathrm{mmol} / \mathrm{L}$. Subjects were excluded if they had a history of cardiovascular disease, previously diagnosed diabetes, hypertension or hypothyroidism, or were treated with cholesterol-lowering agents. Other exclusion factors included reported lactose intolerance, alcohol intake of more than 10 drinks/wk and use of antioxidant supplements within the previous two months. Thirteen men met these criteria, ages 27 to $61 \mathrm{yr}(47 \pm 9, \mathrm{x} \pm \mathrm{SD} \mathrm{y})$. Eleven subjects were initially recruited and 2 more were added to the group 2 weeks later. Subjects' body mass indices ranged from 26 to $38 \mathrm{~kg} / \mathrm{m}^{2}\left(30.2 \pm 4.4 \mathrm{~kg} / \mathrm{m}^{2}\right)$. Mean serum cholesterol levels at screening were $6.54 \pm 0.78 \mathrm{mmol} / \mathrm{L}$. The experimental procedures and protocol were approved by the Ethical Committee on Human Research of McGill University. Informed consent form was signed by all subjects before the start of the study.

\section{The diet}

A randomized, crossover placebo-controlled design was used where research subjects consuming self-selected diets supplemented their intake with $500 \mathrm{~mL} / \mathrm{d}$ of either kefir (Liberty Co, Candiac, Quebec) or milk, each over a $4 \mathrm{wk}$ period. Seven subjects received the kefir supplement in the first period while 6 subjects received milk first. During the second supplementation period, subjects consumed the alternate supplement. Supplementation periods were separated by a $4 \mathrm{wk}$ washout period. Both products were flavored with $60 \mathrm{~g} /$ serving of either peach or strawberry puree. The milk supplement was prepared daily by adding $90 \mathrm{~mL}$ of skim milk powder to $380 \mathrm{~mL}$ of $2 \%$ milk and $100 \mathrm{~mL}$ of water to produce a volume equal to that of kefir. Both products were thus designed to contain the same fat and cholesterol content as well as energy value (Table 1). Subjects consumed dairy supplements under supervision during weekdays and at home over the weekend. Habitual breakfast foods of each subject were available to consume with the dairy product. Throughout the trial, subjects were asked to maintain their habitual diet and exercise at a level consistent with that before study onset. Food frequency questionnaires were administered after the washout period and after period 2 of the trial to assess changes in consumption of dairy products.

\section{Biological sample collection}

Fasting blood samples $(20 \mathrm{~mL})$ were taken on days 1,8 , $15,22,28$ and 29. All blood samples were centrifuged at $1500 \mathrm{rpm}$ for $15 \mathrm{~min}$ at $4^{\circ} \mathrm{C}$. Plasma and red blood cells were immediately separated and stored at $-80^{\circ} \mathrm{C}$ for later analysis. A deuterium $\left(\mathrm{D}_{2} \mathrm{O}\right)$ dose of $0.7 \mathrm{~g} / \mathrm{kg}$ estimated body water was given on day 28 of each period for analysis of FSR of cholesterol. Body water was assumed to be $60 \%$ of total body weight. Subjects were supplied with deuterium-labeled drinking water $\left(0.93 \mathrm{~g} \mathrm{D}_{2} \mathrm{O} / \mathrm{L}\right.$ of water) over the $24 \mathrm{~h}$ period following the initial deuterium dosing to maintain body water enrichment at plateau. A final fasting blood sample was taken exactly $24 \mathrm{~h}$ after the pre-dose sample. Samples of fecal material were collected by each subject on day before the onset of each period (day 0) and at the end (day 28) of each supplementation period.

Table I: Comparison of the nutritive value of kefir and milk

Kefir Milk

\begin{tabular}{lll}
\hline & \multicolumn{3}{c}{ Unit/500 mL } \\
Energy, kJ (kcals) & $1200(287)$ & $1200(287)$ \\
Fat, g & 7.6 & 7.6 \\
Protein, g & 23.6 & 23.6 \\
Carbohydrates, g & 31.2 & 31.2 \\
Cholesterol, mg & 311 & 35
\end{tabular}

I Extrapolated from originating milk. 


\section{Cholesterol analyses}

Total cholesterol, HDL-cholesterol, and triglyceride concentrations in plasma at each time point were analyzed in quadruplicate using a VP Auto-analyzer (Abbott Instruments, Montréal, Québec). The instrument was calibrated using reagents and known standard concentrations of total cholesterol, HDL-cholesterol, and triglycerides (Sigma Laboratories, Oakville, Ontario). Low-density lipoprotein cholesterol levels were calculated using the Friedewald formula [18].

\section{Cholesterol synthesis measurement}

For measurement of daily rate of cholesterol synthesis, lipids were extracted from approximately $2 \mathrm{~g}$ of red blood cells [19]. Extracted lipids were spotted on thin-layer silica gel plates $(20 \mathrm{~cm} \times 20 \mathrm{~cm}, 250 \mathrm{~mm})$. Unesterified cholesterol bands were recovered and combusted to obtain the resulting combustion water. Plasma water deuterium enriched samples were diluted 6 times to reduce the level of enrichment to working levels. Analysis of product hydrogen gas deuterium enrichment was achieved using a dual inlet ratio mass spectrometer (VG Isogas 903D, Cheshire). The mass spectrometer was calibrated daily using SMOW and GISP standards.

Cholesterol FSR was defined as the daily fraction of free exchangeable cholesterol that is newly synthesized. FSR was calculated from the measured change in product deuterium enrichment in $24 \mathrm{~h}$ relative to the maximum precursor deuterium enrichment determined from the body water pool [20].

\section{Fecal pH, SCFA and bacterial contents}

Fecal samples were collected from 11 subjects since 2 subjects were recruited into the trial after the samples from the first subjects were collected. Samples were collected in clean plastic containers, refrigerated overnight and then aliquoted. Fecal material ( $2 \mathrm{~g}$ ) was added to a glass vial containing $8 \mathrm{~mL}$ of distilled water, the contents mixed and then frozen until pH measurements were taken. Fecal material ( $2 \mathrm{~g}$ ) was added to a glass vial containing $8 \mathrm{~mL}$ of $80 \%$ ethanol, the contents mixed and then stored at $-4^{\circ} \mathrm{C}$ until extracted for SCFA analyses. Samples were extracted using the method of Erfle et al [21], using isocaproic acid as an internal standard. A Perkin Elmer Autosystem gas chromatograph fitted with a $30 \mathrm{~m}$ DB-FFAP capillary column $(0.25 \mathrm{~mm}$ ID, $0.25 \mu \mathrm{m})$ (J\&W Scientific, Brockville, Ontario) was used to quantify acetic, propionic, isobutyric, butyric, isovaleric, and valeric acid by comparing peak areas to those of pure standards of known concentration. Fecal dry matter was determined by weighing triplicate fecal samples before and after heating at $90^{\circ} \mathrm{C}$ for $24 \mathrm{~h}$. Data were expressed on a per g dry matter basis.

\section{Statistical analyses}

Endpoints (average of days 28 and 29) and changes from baseline for plasma TC, LDL-cholesterol, HDL-cholesterol, and TG concentrations for each period were compared for treatment differences using paired Student's t-test (SAS/STAT version 6.12, SAS Institute, Cary, NC). Differences between cholesterol FSR after kefir and milk supplementation were also compared using Student's paired ttest. Plasma fatty acid proportions on day 28 of each phase were compared using Student's t-test. Repeated measures analysis of variance of results was carried out using the General Linear Model Procedure (SAS/STAT version 6.12, SAS Institute, Cary, NC) to analyse differences in fecal SCFA with diet and time as variables in the model. Data for $\mathrm{pH}$ were transformed to their anti-logarithm before statistical analyses, as suggested by Carman et al [22]. Data are reported as mean \pm SD.

\section{Results}

According to our observations, subjects complied with the protocol, with one exception where a subject did not consume the placebo product. Gastrointestinal disturbances were reported during both supplementation periods. Two subjects reported cramping and constipation at the onset of kefir supplementation. With milk consumption, one subject complained of feelings of bloating and having loose stools, while two subjects reported increased stool frequency or cramps. All complaints occurred during the first week of supplementation with kefir or milk. After the initial week, both products were well tolerated. Subjects consumed the same breakfast foods in both supplementation periods.

Initial mean body weight of subjects prior to kefir and milk supplementation was $90.2 \pm 4.0 \mathrm{~kg}$ and $90.3 \pm 4.1 \mathrm{~kg}$, respectively. Individual body weights varied by -0.9 to 2.7 $\mathrm{kg}$ and -3.2 to $1.4 \mathrm{~kg}$ during kefir and milk supplementation, respectively (not significant).

Percent changes in total plasma cholesterol and HDL-cholesterol concentrations of subjects after kefir and milk supplementation periods are shown in Figure 1. There was no effect of diet or time on total, HDL- and LDL-cholesterol concentrations. Data at baseline, endpoint and change during each supplementation period are shown in Table 2. The endpoint plasma total cholesterol levels after kefir supplementation $(6.51 \pm 1.05 \mathrm{mmol} / \mathrm{L})$ was not different from that after milk supplementation $(6.00 \pm 1.25 \mathrm{mmol} /$ $\mathrm{L})$. Changes in TC concentrations from baseline were not different between kefir and milk supplementation. For HDL-cholesterol concentrations, the endpoint values were $1.05 \pm 0.22 \mathrm{mmol} / \mathrm{L}$ after kefir supplementation and $1.02 \pm 0.22 \mathrm{mmol} / \mathrm{L}$ after milk supplementation. There was no difference between kefir and milk in the change in HDL-cholesterol concentrations from baseline. Similarly, 


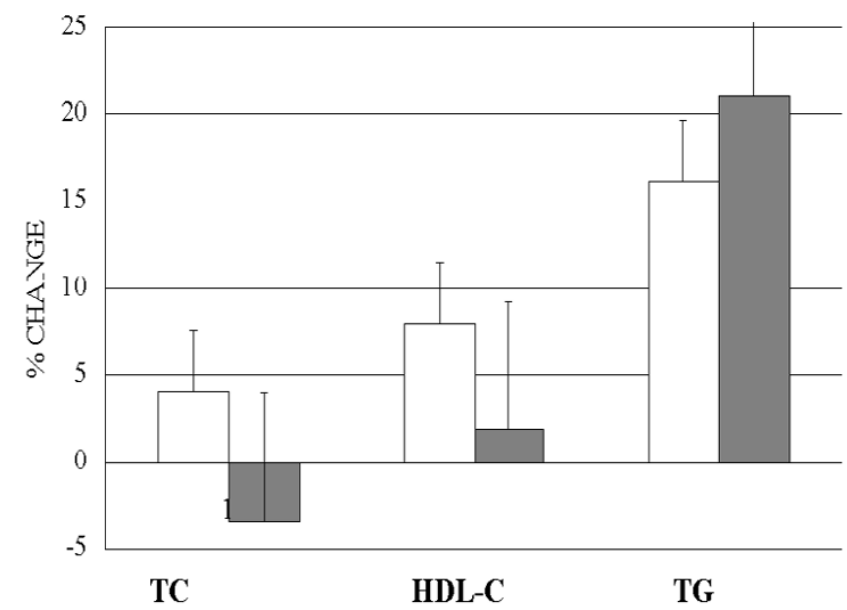

\section{Figure I}

Change in plasma total cholesterol, HDL-cholesterol and triglyceride levels in male subjects after kefir and milk supplementation. $\square=$ kefir supplementation; - = milk supplementation. Values are means $\pm S D, n=13$.

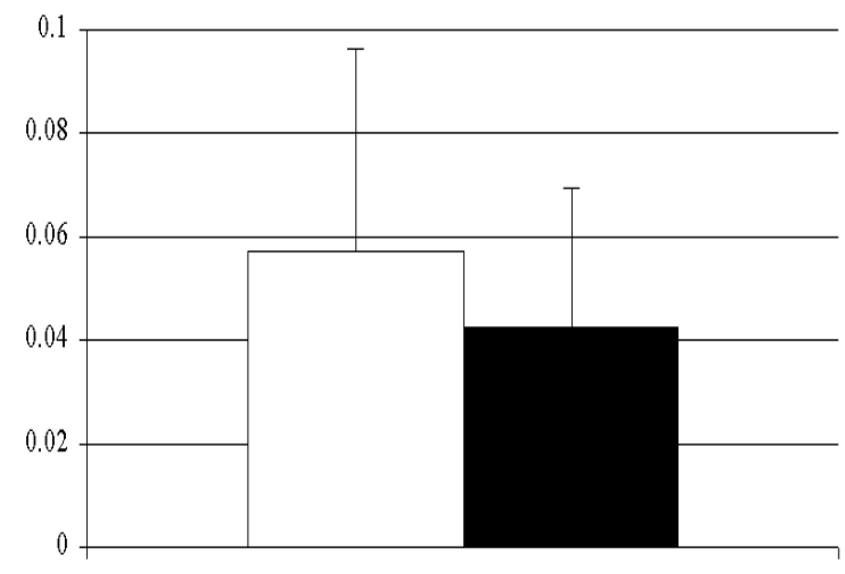

FSR

\section{Figure 2}

Comparison of fractional synthetic rates of cholesterol after kefir and milk supplementation. $\square=$ kefir supplementation; $=$ milk supplementation. Values are means $\pm S D, n=I 3$.

the endpoint LDL-cholesterol concentration after kefir supplementation $(5.43 \pm 1.17 \mathrm{mmol} / \mathrm{L})$ and change in LDL-cholesterol from baseline $(0.01 \pm 0.68 \mathrm{mmol} / \mathrm{L})$ were not different from milk supplementation $(4.93 \pm 1.22$ $\mathrm{mmol} / \mathrm{L}$ and $-0.13 \pm 0.97 \mathrm{mmol} / \mathrm{L}$, respectively). There was no effect of kefir or milk consumption on total cholesterol: HDL-cholesterol or LDL: HDL-cholesterol ratios.

Endpoint triglyceride concentrations were also not affected by kefir or milk supplementation (3.12 \pm 1.51 vs 3.21 $\pm 1.58 \mathrm{mmol} / \mathrm{L}$, respectively, Figure 1). Triglyceride concentrations at baseline, endpoint and change during each supplementation period were not significantly different between kefir and milk consumption and are shown in table 2.

Fractional synthesis rates for red cell free cholesterol were not different after kefir supplementation relative to milk supplementation (Figure 2). The mean group FSR were $0.057 \pm 0.043$ and $0.043 \pm 0.033$ pools/d for kefir and milk supplementation, respectively.

Of the 11 subjects from whom fecal samples were collected, $8(73 \%)$ were found to have increased bacterial concentration with kefir supplementation. Only 3 (27\%) of the subjects had greater fecal bacterial counts after milk supplementation. There was no correlation between fecal bacterial content and any of the blood lipid parameters analyzed.

Acetic acid was the fecal SCFA found in highest concentrations followed by propionic acid and then butyric acid both at baseline and $28 \mathrm{~d}$ (Table 3 ). The ratio of acetic/ propionic/butyric was approximately $45 / 17 / 15$ at $0 \mathrm{~d}$ for both groups. Significant $(p<0.05)$ time effects were found for isobutyric, isovaleric, propionic and the total amount of SCFA. For all four acids, day 28 values were greater than day 0 values for both the kefir and the milk treatments. There was no treatment effect on fecal SCFA levels. Fecal pH measurements were not affected by treatment.

\section{Discussion}

Results of this study do not support the use of kefir in the management of hyperlipidemia. Neither kefir nor milk supplementation decreased total cholesterol, HDL-cholesterol, LDL-cholesterol, or triglyceride concentrations. Similarly, there was no difference in cholesterol FSR between supplementation periods. In addition, plasma fatty acids levels remained constant throughout both supplementation phases. Both kefir and milk supplementation resulted in increased SCFA recovery in fecal material over time but these changes in SCFA were not significantly different between treatments.

Kefir is an ancient fermented milk product that originates in the Caucasian mountains of Asia. It has been widely recommended in Soviet countries for consumption by healthy individuals as well as by patients with gastrointestinal and metabolic disease, hypertension, ischemic heart disease and allergy [1]. However, literature supporting kefir's proposed health benefits is scarce [2]; we must thus rely on studies conducted on yogurts and other fermented dairy products regarding its efficacy. 
Table 2: Plasma lipid concentrations ( $\mathbf{m m o l} / \mathrm{L}$ ) with consumption of a kefir or milk supplement for $28 \mathrm{~d}$.

\begin{tabular}{|c|c|c|c|c|c|}
\hline Supplement & & $\mathrm{TC}$ & HDL-C & LDL-C & TG \\
\hline \multirow[t]{3}{*}{ Kefir } & Baseline & $6.46 \pm 1.43$ & $1.04 \pm 0.29$ & $5.41 \pm 1.45$ & $3.03 \pm 1.87$ \\
\hline & Endpoint & $6.51 \pm 1.13$ & $1.05 \pm 0.22$ & $5.43 \pm 1.17$ & $3.03 \pm 1.52$ \\
\hline & Change & $0.05 \pm 0.74$ & $0.01 \pm 0.19$ & $0.01 \pm 0.68$ & $0.00 \pm 1.16$ \\
\hline \multirow[t]{3}{*}{ Milk } & Baseline & $6.08 \pm 1.04$ & $1.01 \pm 0.25$ & $5.06 \pm 1.04$ & $2.87 \pm 1.60$ \\
\hline & Endpoint & $6.00 \pm 1.25$ & $1.02 \pm 0.22$ & $4.93 \pm 1.22$ & $3.01 \pm 1.30$ \\
\hline & Change & $-0.08 \pm 0.89$ & $0.00 \pm 0.27$ & $-0.13 \pm 0.97$ & $0.14 \pm 0.87$ \\
\hline
\end{tabular}

Values are means $\pm S D, n=13$. Endpoints and change from baseline were tested for differences between diets with paired Student's t-tests.

Table 3: Fecal short chain fatty acid ( $\mu \mathrm{mol} / \mathrm{L}$ per $\mathrm{g}$ dry matter) and $\mathrm{pH}$ after kefir or milk consumption

\begin{tabular}{|c|c|c|c|c|}
\hline & \multicolumn{2}{|c|}{ KEFIR } & \multicolumn{2}{|r|}{ MILK } \\
\hline SCFA & Day 0 & Day 28 & Day 0 & Day 28 \\
\hline Acetic & $247 \pm 110$ & $278 \pm 129$ & $228 \pm 77$ & $269 \pm 104$ \\
\hline Butyric & $80 \pm 53$ & $99 \pm 61$ & $77 \pm 38$ & $75 \pm 36$ \\
\hline |sobutyric| & $8.6 \pm 4.1$ & $10 \pm 6.9$ & $7.8 \pm 2.5$ & $11 \pm 3.9$ \\
\hline Valeric & $13 \pm 6$ & $13 \pm 6$ & $13 \pm 7$ & $14 \pm 7$ \\
\hline Isovaleric I & $14 \pm 5$ & $16 \pm 8$ & $12 \pm 4$ & $17 \pm 6$ \\
\hline Propionic ${ }^{1}$ & $95 \pm 52$ & $117 \pm 66$ & $85 \pm 42$ & $105 \pm 61$ \\
\hline Total SCFA I & $458 \pm 192$ & $535 \pm 239$ & $423 \pm 149$ & $492 \pm 196$ \\
\hline Fecal $(\mathrm{pH})$ & $6.5 \pm 0.5$ & $6.8 \pm 0.6$ & $6.5 \pm 0.5$ & $6.7 \pm 0.4$ \\
\hline
\end{tabular}

Values are means $\pm S D, n=12$. Isignificant effect of time during both kefir and milk supplementation, $p<0.05$.

This study is the first conducted to establish whether kefir has probiotic activity on plasma cholesterol concentrations and its synthesis. Our hypothesis was that fermented milk products could reduce circulating cholesterol levels. Other fermented milk products had previously been shown to have hypocholesterolemic properties in humans [8-13]. Several strains of bacteria, such has Lactobacilli and Streptococci, have been shown to reduce serum cholesterol levels in men $[8,13]$. These bacteria are normally transient microorganisms in the gastrointestinal tract (GIT), entering with food or saliva. Chronic ingestion of fermented dairy products, which contain milk proteins that are protective for bacterial survival throughout the GIT [17], can lead to modifications of the colonic flora [23]. In the GIT, bacteria can produce several effects that can result in lower plasma cholesterol levels.

One mechanism by which colonic bacteria can alter cholesterol concentrations in plasma is via bile acid deconjugation. Deconjugated bile acids are excreted in the feces
[5], whereas non-conjugated bile acids are recycled to the liver via the enterohepatic circulation. Their excretion in fecal material results in increased cholesterol use for de novo bile acid synthesis. Decreased cholesterol synthesis would result in decreased body cholesterol pools. This would in turn lead to lower total to LDL-cholesterol pools and diminish cardiovascular risk. Data to support this mechanism were not obtained in the present study. Although this mechanism was not explored in the present study, data suggest that bile acid deconjugation is a plausible means by which bacteria can modulate plasma cholesterol concentrations.

Colonic bacteria could also exert a hypocholesterolemic effect via their production of SCFA. Wolever et al [24] showed that colonic propionate inhibits acetate's cholesterol-generating effects. Therefore, for gut bacterial fermentation to be hypocholesterolemic, sufficient propionate must be produced to offset the effects of acetate, which is a precursor for cholesterol synthesis. In- 
creasing gut bacterial content and composition may result in altered patterns of SCFA production in the colon that could result in beneficial effects on plasma cholesterol levels. Our data would indicate that the bacteria in kefir may not produce sufficient propionate to be effective in impacting on cholesterol synthesis.

In the present study, no effect of kefir or milk was observed on lipid levels. The lack of significant effect of kefir on total cholesterol concentration is similar to studies using milk inoculated with bacteria reported by Thompson et al [15] and De Roos et al [16] as well as animal studies using fermented milk as observed Rao et al [7]. However, several other studies did show a positive effect of milk $[25,26]$ and fermented milks $[8,10,13]$. The presence of confounders, such as the fat content of the diets $[14,15]$ and undefined bacterial composition [14] and concentration [15] account for differences in the results obtained and make comparisons between studies difficult. Also, the use of a proper placebo for studies investigating fermented milks is problematic since milk has been shown to possess hypocholesterolemic properties $[25,26]$.

Kefir supplementation, but not milk, produced a significant increase in fecal propionic acids without an accompanying change in fecal acetic acid levels. Therefore, present data suggest that the rise in propionate was not sufficient to inhibit acetate's actions as a precursor for cholesterol synthesis. As our results show, cholesterol synthesis was not altered by kefir consumption, and thus, plasma cholesterol concentrations were maintained at baseline levels. Thus, the lack of effect of kefir on plasma cholesterol concentrations could have been due in part to a lack of sufficient increase in propionic acid concentrations. Further studies are required to establish the level of ingested bacteria needed to result in larger increases in propionic acid production. The level of propionic acid production necessary to produce a desirable effect on blood cholesterol profile also remains to be determined.

The lack of effect of kefir on plasma lipid concentrations in this trial may have several possible explanations. If bile acid deconjugation by bacteria is the main mode of action of bacteria on plasma cholesterol levels, then perhaps the bacterial content of the kefir was not adequate to cause a sufficient rise in colonic bacterial content. The kefir supplement consumed in this trial contained $10^{9}$ colonyforming units (CFU). Saxelin et al [27] found that a bacterial concentration of $10^{11}$ was required in order to produce colonization in all subjects. In this study only 8 out of 11 subjects analyzed for fecal bacterial content contained the minimum detection level of $10^{3} \mathrm{CFU} / \mathrm{g}$ dry matter. On the other hand, if the increased propionate level is the major mechanism of action, then perhaps the type of bacteria present in kefir do not preferentially pro- duce propionate over acetate and hence, would not inhibit cholesterol synthesis and lead to diminished circulating cholesterol levels.

\section{Conclusions}

Although it is not possible from our data to firmly establish the reasons for the lack of effect of kefir on plasma cholesterol levels, present results do not support consumption of kefir as a probiotic to lower plasma cholesterol levels. The type and concentration of bacteria contained in kefir may not have been adequate to produce an impact on cholesterol metabolism. Thus, in the amounts given in this study, kefir consumption does not affect cholesterol metabolism and would therefore not be of clinical value in the management of hypercholesterolemia.

\section{Competing interests}

None declared.

\section{References}

I. NS Koroleva: Technology of kefir and kumys. Fed Int Laiterie Int Dairy Fed Bull. 1988, 227:96-100

2. Farnworth ER: Kefir: from folklore to regulatory approval. J Nutraceut Functional \& Medical Fd 1999, I:57-68

3. Akalin AS, Gonc S, Duzel S: Influence of yogurt and acidophilus yogurt on serum cholesterol levels in mice. J Dairy Sci I997, 80:2721-2725

4. Beena A, Prasad V: Effect of yogurt and bifidus yogurt fortified with skim milk powder, condensed whey and lactose-hydrolyzed condensed whey on serum cholesterol and triacylglycerol levels in rats. J Dairy Res 1997, 64:453-457

5. Gilliland SE, Speck ML: Deconjugation of bile acids by intestinal Lactobacilli. Appl Environ Microbiol 1977, 33:15-18

6. Nakajima H, Suzuki Y, Hirota T: Cholesterol-lowering activity of ropy fermented milk. J Food Sci 1992, 57:I327-I329

7. Rao DR, Chawan CB, Pulusani SR: Influence of milk and thermophilus milk on plasma cholesterol and hepatic cholesterogenesis in rats. J Food Sci 1981, 46:I339-I34I

8. Agaerbaeck M, Gerdes LU, Richelsen B: Hypocholesterolemic effect of a new fermented milk product in healthy middle-aged men. Eur J Clin Nutr 1995, 49:346-352

9. Hepner G, Fried R, St. Jeor S, Fusetti L, Morin R: Hypocholesterolemic effect of yogurt and milk. Am J Clin Nutr 1979, 32:19-24

10. Richelsen B, Kristensen K, Pedersen SB: Long-term (6 months) effect of a new fermented milk product on the level of plasma lipoproteins-a placebo-controlled and double blind study. Eur J Clin Nutr 1996, 50:81 I-8I5

II. Schaafsma G, Meuling WJA, van Dokkum W, Bouley C: Effects of a milk product, fermented by Lactobacillus acidophilus and with fructo-oligosaccharides added, on blood lipids in male volunteers. Eur J Clin Nutr 1998, 52:436-440

12. Steinmetz KA, Childs MT, Stimson C, Kushi LH, McGovern PG, Potter JD, Yamanaka WK: Effect of consumption of whole milk and skim milk on blood lipid profiles in healthy men. Am J Clin Nutr 1994, 59:6 I 2-618

13. Bertolami MC, Faludi AA, Batlouni M: Evaluation of the effects of a new fermented milk product (Gaio) on primary hypercholesterolemia. Eur J Clin Nutr 1999, 53:97-I0I

14. Rossouw JE, Burger EM, Van der Vyver P, Ferreira J: The effect of skim milk, yoghurt, and full cream milk on human serum lipids. Am J Clin Nutr 1981, 34:35 I-356

15. Thompson LU, Jenkins DJA, Vic Amer MA, Reichert R, Jenkins A, Kamulsky J: The effects of fermented and unfermented milks on serum cholesterol. Am J Clin Nutr 1982, 36: I I 06- I I I I

16. de Roos NM, Schouten G, Katan MB: Yoghurt enriched with Lactobacillus acidophilus does not lower blood lipids in healthy men and women with normal to borderline high serum cholesterol levels. Eur J Clin Nutr 1998, 53:277-280 
17. Charteris WP, Kelly PM, Morelli L, Collins JK: Development and application of an in vitro methodology to determine the transit tolerance of potentially probiotic Lactobacillus and Bifidobacterium species in upper human gastrointestinal tract. J App Microbiol I 998, 84:759-768

18. Friedewald WT, Levy RI, Fredericson DS: Estimation of the concentration of low-density lipoprotein cholesterol in plasma without diffuse use of preparative ultracentrifugation. Clin Chem 1979, I 8:499-502

19. Folch J, Lees M, Stanley GHS: A simple method for the isolation and purification of total lipids from animal tissues. J Biol Chem 1957, 226:497-509

20. Jones PJH, Lichtenstein AH, Schaeffer EJ: Interaction of dietary fat saturation and cholesterol level on cholesterol synthesis measured using deuterium incorporation. J Lipid Res 1994, 35:1093-1101

21. Erfle JD, Mahadevan S, Sauer FD: The effect of diet quality on adenosine-5'-triphosphate concentration and adenylate energy charge of rumen microbes in fistulated cows. J Dairy Sci 1979 , 62:284-291

22. Carman RJ, Van Tassell RL, Wilkins TD: Interactions between dietary compounds and the colonic microflora. In: Science for the Food Industry of the 2 I st Century, Biotechnology, Supercritical Fluids, Membranes and other Advanced Technologies for Low Calorie, Healthy Food Alternatives 1993313-342

23. Marteau P, Pochart P, Flourie B, Pellier P, Santos L, Desjeux JF, Rambaud JC: Effect of chronic ingestion of a fermented dairy product containing Lactobacillus acidophilus and Bifidobacterium bifidum on metabolic activities of the colonic flora in humans. Am J Clin Nutr 1990, 52:685-688

24. Wolever TMS, Spadafora P, Eshuis $\mathrm{H}$ : Interaction between colonic acetate and propionate in humans. Am J Clin Nutr 1991, 53:68I-687

25. Buonopane G], Kilara A, Smith JS, McCarthy RD: Effect of skim milk supplementation on blood cholesterol concentration, blood pressure, and triglycerides in a free-living human population. I Am Coll Nutr 1992, I I:56-67

26. Golay A, Ferrera J-M, Felber J-P, Schneider H: Cholesterol-lowering effect of skim milk from immunized cows in hypercholesterolemic patients. Am J Clin Nutr 1990, 52:1014-1019

27. Saxelin M, Elo S, Salminen S, Vapaatalo J: Dose response colonisation of faeces after oral administration of Lactobacillus casei strain GG. Am J Clin Nutr 199I, 59:929-934

Publish with BioMed Central and every scientist can read your work free of charge

"BioMedcentral will be the most significant development for disseminating the results of biomedical research in our lifetime."

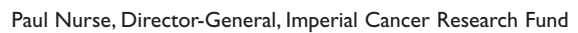

Publish with BMC and your research papers will be:

- available free of charge to the entire biomedical community

- peer reviewed and published immediately upon acceptance

- cited in PubMed and archived on PubMed Central

- yours - you keep the copyright

Submit your manuscript here:

http://www.biomedcentral.com/manuscript/
BioMedcentral.com editorial@biomedcentral.com 